\title{
A STUDY ON THE CLINICAL AND HORMONAL PROFILE OF THE PATIENTS WITH HIRSUTISM
}

\author{
by Neerja Puri
}

comment:

Daisuke Tsuruta, MD PhD

Dr. Puri underwent analyses of 50 hirsutism patients in light particularly of virilization clinically, causes of hirsutism, associated diseases of hirsutism and pervic ultrasonograpy [1]. The population of hirsutism patients is relatively high considering that hirsutism is rather rare disease. From his/her study, I have known that almost half the hirsutism patients are caused by unknown, idiopathic origin and the other $40 \%$ are by polycystic ovarian disease and rarely by congenital adrenal hyperplasia or hypothyroidism. The major underlying diseases of hirsutism are obesity, acne, striae, acanthosis nigricans and menstrual irregularities. So, we have to check and treat these dermatologic or systemic disorders if we see hirsutism patients.

Ultrasonography showed that $40 \%$ of hirsutism patients showed ovarian cysts. These detailedultrasonographic analyses are extremely helpful for physicians: if we see polycystic or monocystic ovary by ultrasonography accidentally, we have to check virilization signs. Further accumulation of patients of hirsutism patients is required to confirm if this speculation is true. I also propose to see if the differences of race can affect these findings. Even so, I was highly impressed by this analysis reported by only one author.

\section{REFERENCES}

1. Puri N: A study on the clinical and hormonal profile of the patients with hirsutism. Our Dermatol Online 2012; 3: 88-90.

\section{Correspondence:}

Dr. Daisuke Tsuruta, PhD

Department of Dermatology, Kurume University School of Medicine, and Kurume University Institute of Cutaneous Cell Biology, Japan

E-mai:dts211@gmail.com 